\title{
Padres y Maestros 50 años de presencia en la educación en España
}

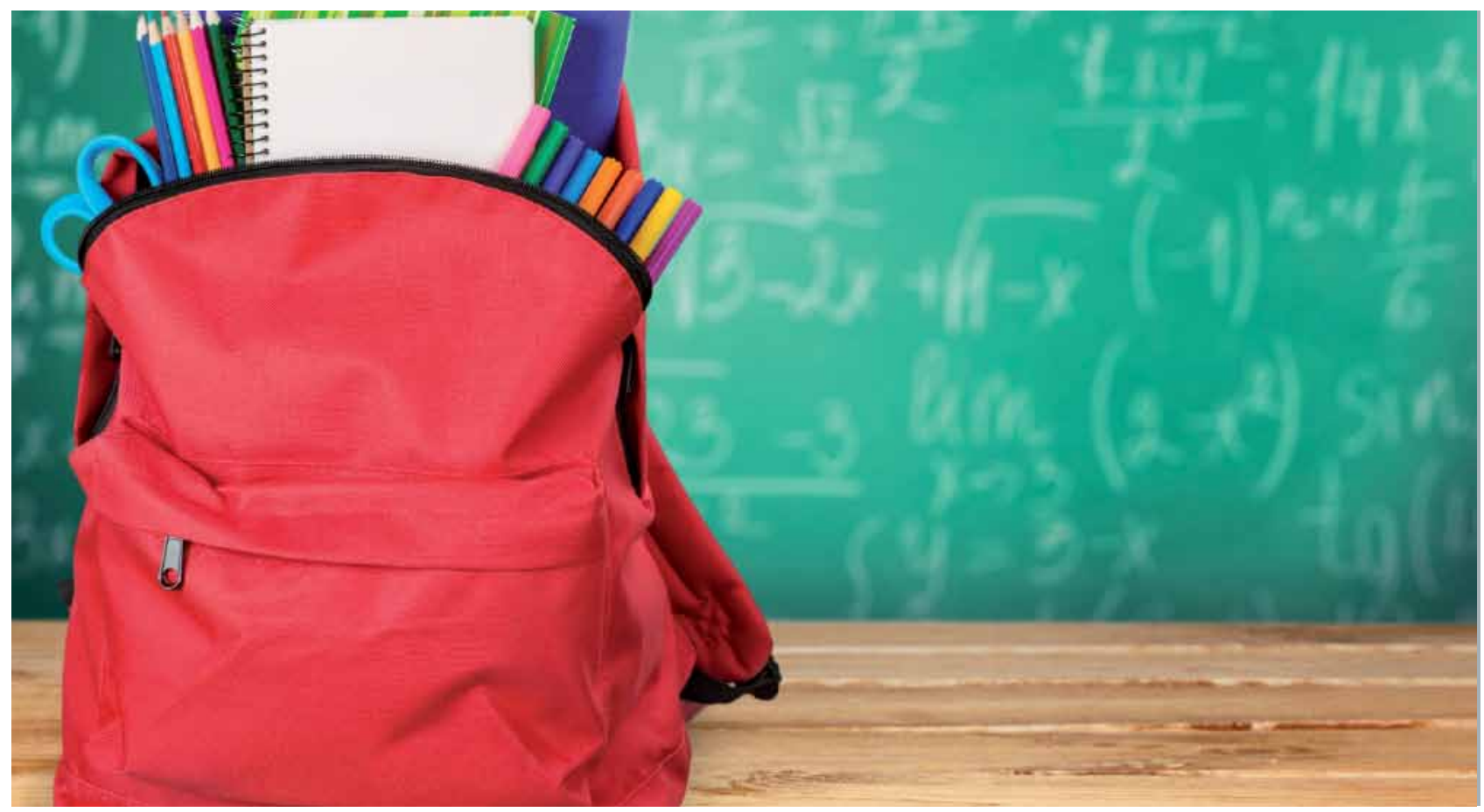

Orígenes y primeros pasos

Nunca una revista nace porque sí. Su triple fin era claro:

1. Servir de ayuda al desarrollo del colegio Santa María del Mar (La Coruña) en su acción pedagógica general.

2. Dedicar una atención especial a la relación de la

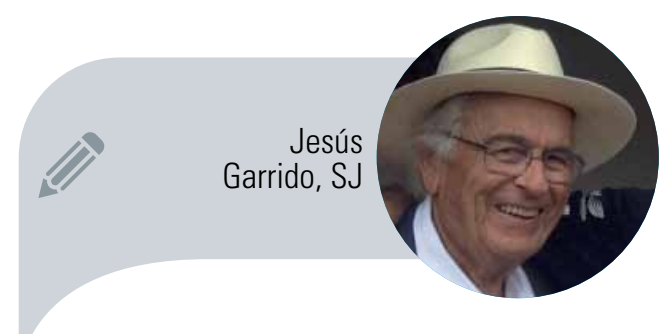

Miembro del equipo fundador de la revista chuchogarrido@icloud.com familia y el colegio.

3. Ejercitar las funciones de divulgación e intercambio con otras publicaciones y sistemas educativos que tuvieran también estos objetivos. 


\section{La buena relación entre los componentes de las escuelas de padres y la cooperación de éstas con los colegios}

¿Cómo estaba entonces, en el curso 1965-1966, la relación entre familia y colegio en diversos países con cierta afinidad al tipo de educación que buscábamos?

En este sentido, recogemos brevemente los primeros datos que históricamente marcan el origen de lo que hoy se llaman "escuelas de padres". Estados Unidos, Francia, Bélgica..., fueron los que iniciaron de una forma sistemática su organización, con los cuales se estableció personalmente, desde el principio, la creación y difusión de Padres y Maestros.

\subsection{Estados Unidos}

1815. Se crea la Asociación de Madres de Familia.

1832. Se edita la primera revista dedicada a la educación familiar de los hijos con el nombre de Mothers Magazine.

1834. Surge una nueva publicación llamada Mothers.

1840. Nace la revista Parents Magazine, cuyo nombre se haría célebre al superar, en los años 50, el millón de lectores y a la cual se añadieron recientemente un sinnúmero de ellas, tales como Mothering, Parenting, Children, Child Education y otras.

1897. Se celebra en EE.UU. el "I Congreso Nacional Parents Teachers".

1923. La Fundación Rockefeller apoya ampliamente la creación de centros de investigación para formar especialistas en la educación de los padres y, con su apoyo decisivo, la Asociación Americana para el Estudio del Niño funda el Consejo Nacional para la Educación de los Padres.

1965. Visita en Nueva York al director de la revista Parents y establecimiento de conexiones con la naciente revista Padres y Maestros del colegio Santa María del Mar de La Coruña.

\subsection{Francia}

1909. La Sra. Moll-Weis funda en París la Escuela para Madres.

\section{Primer número de la revista Padres y Maestros}

Así se mostraba al público': nº 1. C-952- 1965

Título: Padres y Maestros

Colegio Santa María del Mar / La Coruña

Prólogo al no 1: Cuando se empieza...

"Cuando un niño sale de su casa para ir por primera vez a la escuela, avanza felizmente hacia un mundo de horizontes más amplios que aquellos que hasta ahora divisaba desde su hogar. Unos sentimientos nuevos surcarán su corazón.

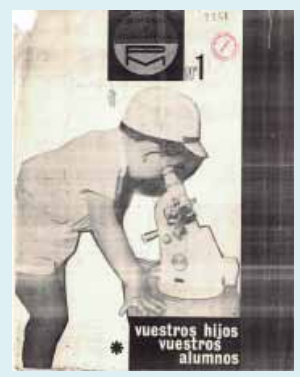
Porque una tercera estrella de autoridad va a surgir en su vida: el maestro. Se sentirá comprendido por él de una manera distinta, porque la mirada del profesor no cae sobre tres o cuatro niños que son "mis hermanos", sino sobre treinta o cincuenta muchachos que serán "mis compañeros" Cuando el rostro de un niño vuelve radiante del colegio no es sólo porque se ha sabido bien una lección. Es porque ha triunfado en la vida; en la vitalidad de un equipo de juego, en el que ha sido bien recibido; en el sentirse justamente enjuiciado y calificado; en la fina apreciación de que su esfuerzo intelectual obtiene un rendimiento proporcionado, sea o no el ideal absoluto. Cuando el rostro de un niño vuelve radiante de la escuela es porque allí se ha encontrado bien. Es la íntima satisfacción de sentirse adaptado a un ambiente que antes no era el suyo".

\section{SUMARI0 del $\mathbf{n}^{0} \mathbf{1}$}

Saber ayudarles / Interpretar los resultados / El padre de familia y el profesor /Curso nuevo, ¿vida nueva? / Padres y Maestros / Salud: sueños y exámenes / Los niños gordísimos / Libros: El mundo de los guiños / Cine: Los olvidados / Consultorio: Una madre angustiada.

1 http://revistas.upcomillas.es/index.php/padresymaestros/issue/view/516

1910. G. Bertier edita para padres la revista Education.

1928. La Sra. Marguerite Lebrun-Vérine crea la que se considera primera escuela de padres en el mundo. La idea fue presentada por ella misma en una conferencia que, invitada por su comité de estudios, pronunció en una sala del Tribunal Supremo de Francia sobre el tema de la educación sexual de los niños. Ella, que se consideraba "mujer de letras" y que estaba casada con un médico, defendió, partiendo de este tema y extendiéndolo a todos los demás, "la necesidad de devolver la confianza a los padres en lo que respecta a su posibilidad de desempeñar debidamente su función educativa", la necesidad de "un mejor conocimiento del niño", "un esfuerzo para conciliar tos principios antiguos de la autoridad paterna con las 


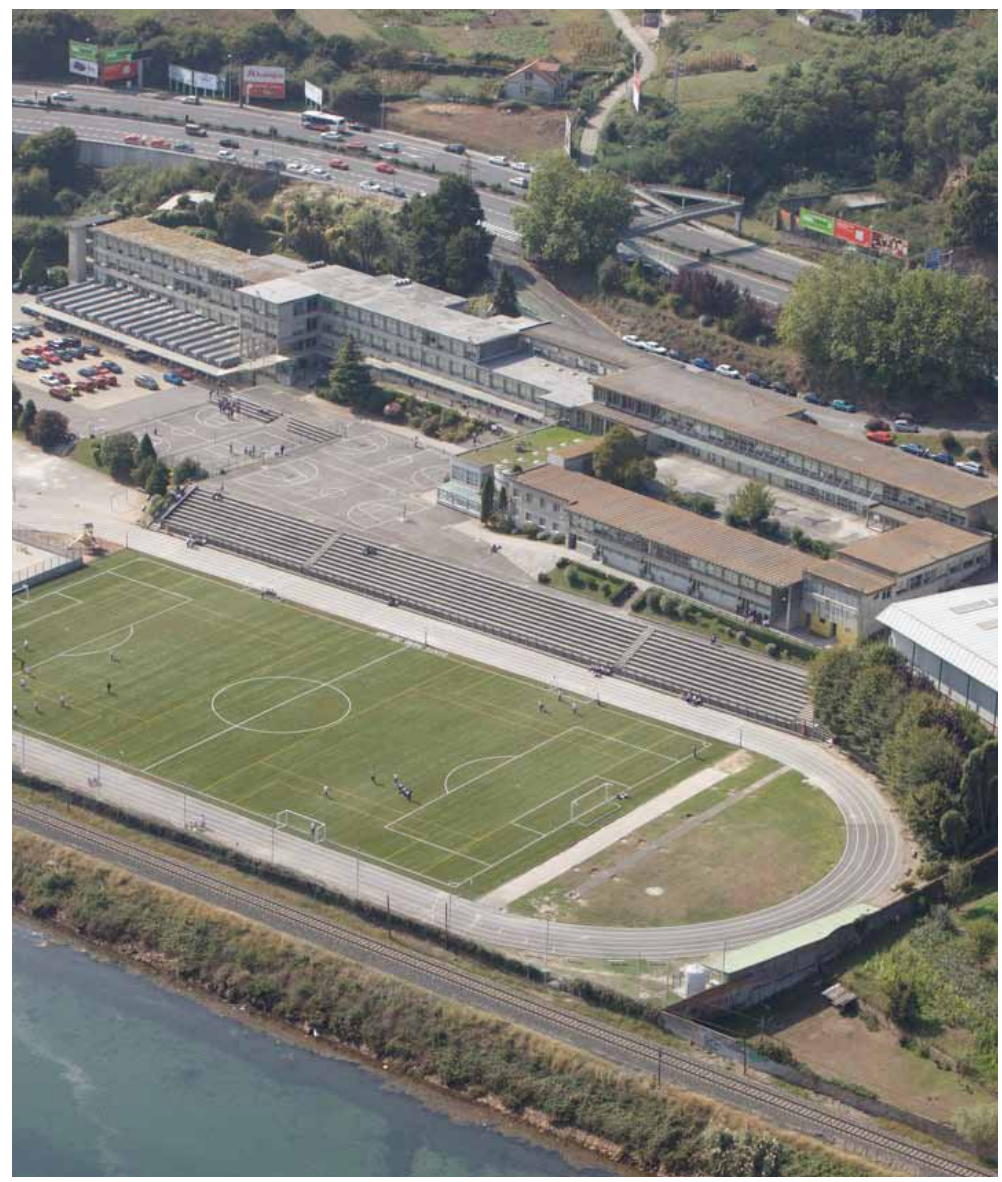

Vista aérea del colegio Santa María del Mar ideas de la autonomía de la persona del niño" y la conciliación de los métodos tradicionales de la enseñanza moral con los métodos activos deformación personal.

1930. La Escuela de Padres francesa publica su primer libro L 'Enfance, en cuyo prólogo la Sra. Vérine defiende la necesidad de una formación continua de los padres.

1939. Se comienzan a impartir de una manera regular y sistemática los primeros cursos para educadores familiares.

1942. La Facultad de Medicina de la Sorbona participa en este tipo de formación para padres y lo integra también de un modo regular en sus actividades, creando más tarde la Cátedra de Neuropsiquiatría Infantil.

1949. Se crea la revista /'École des Parents.

1952. Reconocimiento de utilidad pública a I École des Parents.

1953. Se comienza a editar mensualmente la revista L'Ecole des Parents, que servía antes de boletín de información y que actualmente se ha convertido en la publicación oficial de la FNEPE,
Federation National des Écoles des Parents et des Éducateurs.

1956. Este mismo grupo comienza a editar también la revista trimestral monotemática llamada Le Groupe familial.

1964. Creación de la Fédération Internationale pour IEducatión des Parents Conexión de la revista Padres Maestros (colegio Santa María del Mar, La Coruña (España) con el Dr. A. Berge y Gerard Guasch, profesores en $\mathrm{Ka}$ Sorbonne y en la dirección y consulta de L'Écoles des Parents-EPE.

1965. Creación de la revista Padres y Maestros (PyM) en el colegio Santa María del Mar.

1966. Visita técnica del Dr. Gerard Guasch a la escuela de padres del colegio Santa María del Mar, La Coruña.

Curso de Conductores de Grupo de escuela de padres PyM.

Visita de PyM a L'École des Parents de París.

Curso a Conductores de escuelas de padres de La Coruña.

1970. Creación de la Fédération Nationale des Écoles de Parents et des Éducateurs.

1971. Creación de la línea telefónica Interservice Parents.

1973. Creación del servicio Animation-Formation

http://www.epe-idf.com/decouvrir/ historique

De 1953 a 1975 se mantuvo en Francia la revista Parents et Maitres, dirigida por François Ader SJ y su equipo, y que estaba editada para los colegios católicos de Francia, especialmente, para los jesuitas. Con la dirección de esa revista se estableció contacto ya en1963, tanto por su contenido como por el título que dio origen a Padres y Maestros.

\subsection{Bélgica}

La dirección de la revista Famille, Colléges et Institut del Collège Saint Michel de jesuitas, destinada a padres y profesores, había llegado a una difusión de 25.000 ejemplares, fue visitada en 1963 por Jesús Garri- 


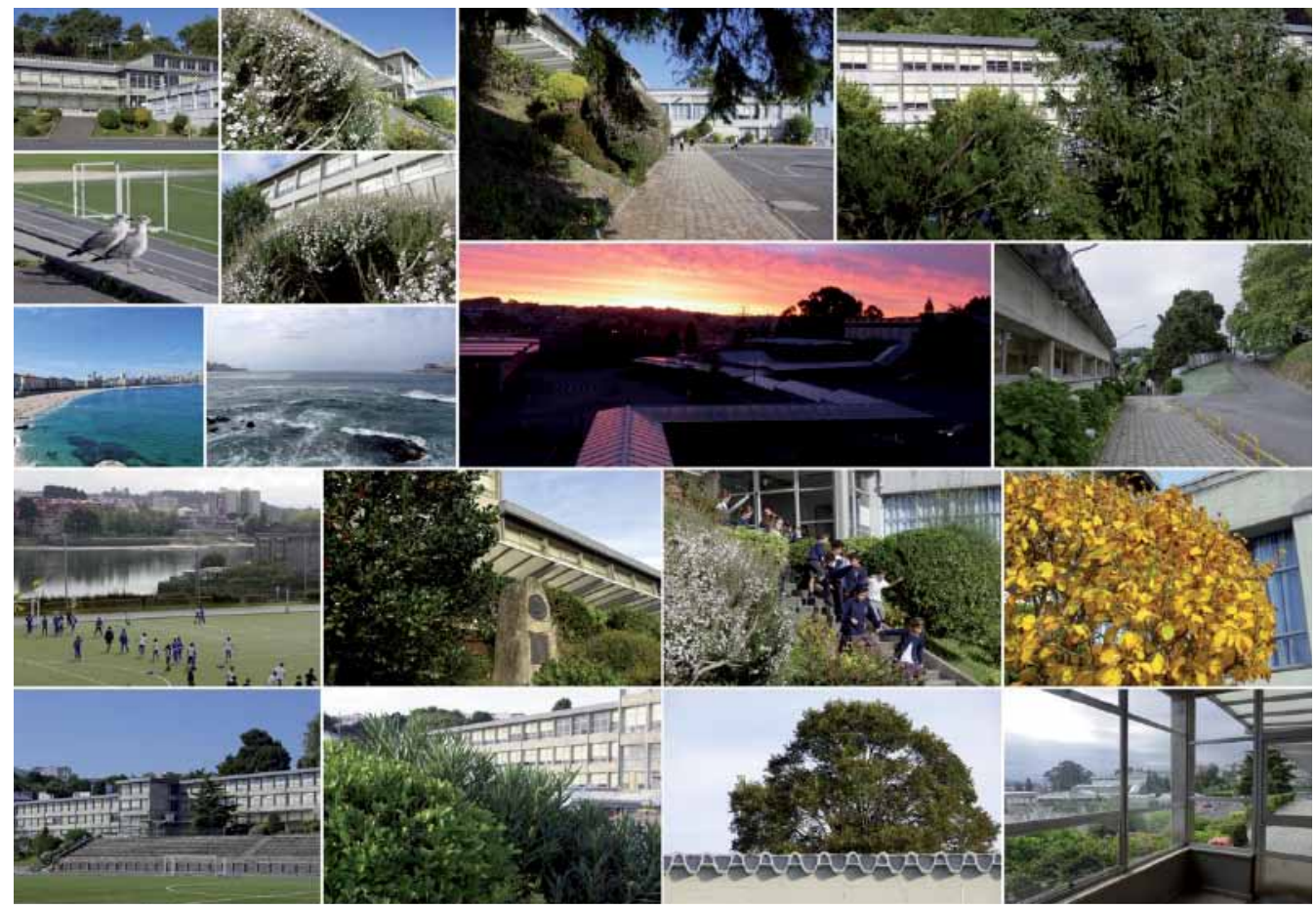

do y sirvió también de enlace para la fundación de la revista de Padres y Maestros.

\section{Escuelas de padres, España}

Revista Diálogo Familia-Colegio. Se comenzó a editar en Granada (1962) en la Congregación Mariana en Granada bajo la promoción y tutela del padre Ferrer SJ y dirigida en su temática por Jesús Garrido SJ. Más tarde, la dirección de la revista pasó a Sevilla.

Surgieron también alrededor de esas fechas otras revistas con temáticas familiares en medio de sus artículos de educación general.

\section{Contenidos de la revista Padres y Maestros}

Debe tenerse en cuenta que la revista Padres y Maestros era el medio de comunicación de las actividades, experiencias, investigaciones que se hacían en el colegio y fue el eco y origen de otras publicaciones. No era algo "añadido" a lo que profesores y padres hacían o inventaban cada día. Por ello se publicaban temas, tal vez no tan interesantes para otros ambientes educativos, pero sí necesarios para la mejora y pulso del trabajo diario en sus aulas, cursos, congresos.

En una primera fase (1965-1972) todos los números fueron temáticos.

1965-1967. El Juego / Niños desobedientes / Las lecturas / Las notas / Revistas y libros para una biblioteca de Padres y Maestros / Sentido religioso / Sentido del cuerpo / Sentido artístico / Sentido artístico / Orientación vital / Encuesta sobre los 5 sentidos.

1968-1970. Ambiente paraescolar / Ambiente familiar / Ambiente escolar / Qué es un profesor / Libro Blanco MEC / Cómo estudiar / Cómo animarles a estudiar / La sinceridad / Premios y castigos / Compañeros.

1970-1972. La Cogestión / Padres / Profesores / Alumnos / Grupos de discusión PyM / Educación sexual / José 18: psicología evolutiva / Experiencia cristiana y evaluación / Los métodos activos explicados a los padres / Aprender a leer: 3 a 13 años / Experiencia cristiana y evaluación.

1972. Sistema de laboratorios: comienza una nueva estructura de la Revista Padres y Maestros con el número 33, donde se establece el sistema de laboratorios, según una clasificación convencional de contenidos: evolutivos, personales, sociales, pedagógicos, didácticos, familiares, ambientales, públicos.

La razón de este cambio se centraba en que la revista Padres y Maestros servía también, además de informar de la actualidad pedagógica, de base documental y activa para el trabajo en las escuelas de padres, de recur- 
De 1953 a I 975 se mantuvo en Francia la revista

Parents et Maitres, dirigida por François Ader S y

su equipo, y que estaba edilada para los colegios

católicos de Francia

so para los consejeros en sus dinámicas de grupo con los alumnos y los profesores en sus departamentos didácticos.

A partir del año 2000 la revista Padres y Maestros adoptó un nuevo formato y estructura.

1973. Conjunto de 4 publicaciones interconectadas que surgieron dentro de la acción de Padres y Maestros en el colegio Santa María del Mar: Revista / Cursos / Cuadernos para Educadores / Teaching Area: profesores

1977. "Prensa Didáctica". La revista anunciaba en su número 54 de enero 1977 la creación de un nuevo proyecto, "Prensa Didáctica", distribuyendo su informe en 6.000 centros escolares de todo el país: 5 periódicos para 5 áreas: sociales, ciencias, espíritu, lenguajes, paraescolares. Describiendo en resumen las actividades que los profesores podrían realizar con sus alumnos trabajando las noticias de actualidad.

ע Congreso Prensa didáctica. 29 agosto - 2 setiembre 1977.

\ Prensa Didáctica se edita en el periódico YA de Madrid (1977).

\ La Voz de la Escuela en La Voz de Galicia. Amplio informe (21 de abril 1982).

\ Suplemento escolar en El Correo español - Pueblo Vasco, Diario de Navarra, Diario de Mallorca, Heraldo de Aragón (1983).

1978. Se crea la sociedad anónima Padres y Maestros entre la Compañía de Jesús, que nombra director a Jesús Garrido, y cuatro socios individuales: Fernando Garrido, Antonio Luengo, Ramón Núñez, Fernando Pariente. Publicaciones: revista Padres y Maestros, Cuadernos para Educadores, Laboratorios de orientación educativa,
Cursos Prensa Didáctica, Biblioteca PyM y cursos de formación educativa. Suscripciones y administración: Dolores Vázquez Alonso. Se fija la residencia de la Sociedad en c/ Fonseca $n^{\circ} 8$, La Coruña.

Cursos de formación: Juegos de Interacción en grupo, Evaluación del Ciclo Inicial y Medio, El cuerpo nunca olvida, Didáctica de las Ciencias, Dirección de Centros Educativos, Escuela de Padres, Interacción Profesor-Alumno, Párvulos, Técnicas de grupo, Entrevista personal, Estilos de aprendizaje, Formación religiosa, Aprendizaje cooperativo, Educación para la ciudadanía, Inteligencias múltiples, Sentido crítico, Resolución Creativa de Problemas, Prensa en la Escuela, Anainas, Pasito a pasito, El caracol, Clarificación de Valores, Educación Preventiva Drogas.

y 1979. Mensual. Revista Padres y Maestros mensual.

У 1983. junio. Se cumplen 100 números de la revista Padres y Maestros.

\ 1991. Padre Maestro Ignacio (14911991). El carácter propio de los colegios jesuitas.

У 1992. América de la A a la Z: V Centenario Descubrimiento

\ 1993. Camino de Santiago: Poetas y romanceros.

\ 1994. Año Internacional de la Familia / 12 temas / 12 meses.

$\checkmark$ 1994. Revista Padres y Maestros $n^{\circ}$ 200.

ע 1995-1996. Páginas centrales. Educación religiosa en familia, Año del Aprendizaje permanente, Ruta Quetzal, Goya, La ciencia en la calle, La Universidad de Santiago cumple 500 años. Cesa la sociedad Padres y Maestros.

\section{Biblioteca Padres y Maestros}

Comunidad educativa, Crecer, Cuadernos de pedagogía, Delta, Cuadernos de orientación familiar, Ecca radio, jesuitas-Canarias, familia cristiana, hacer familia, Ser padres y otras. 


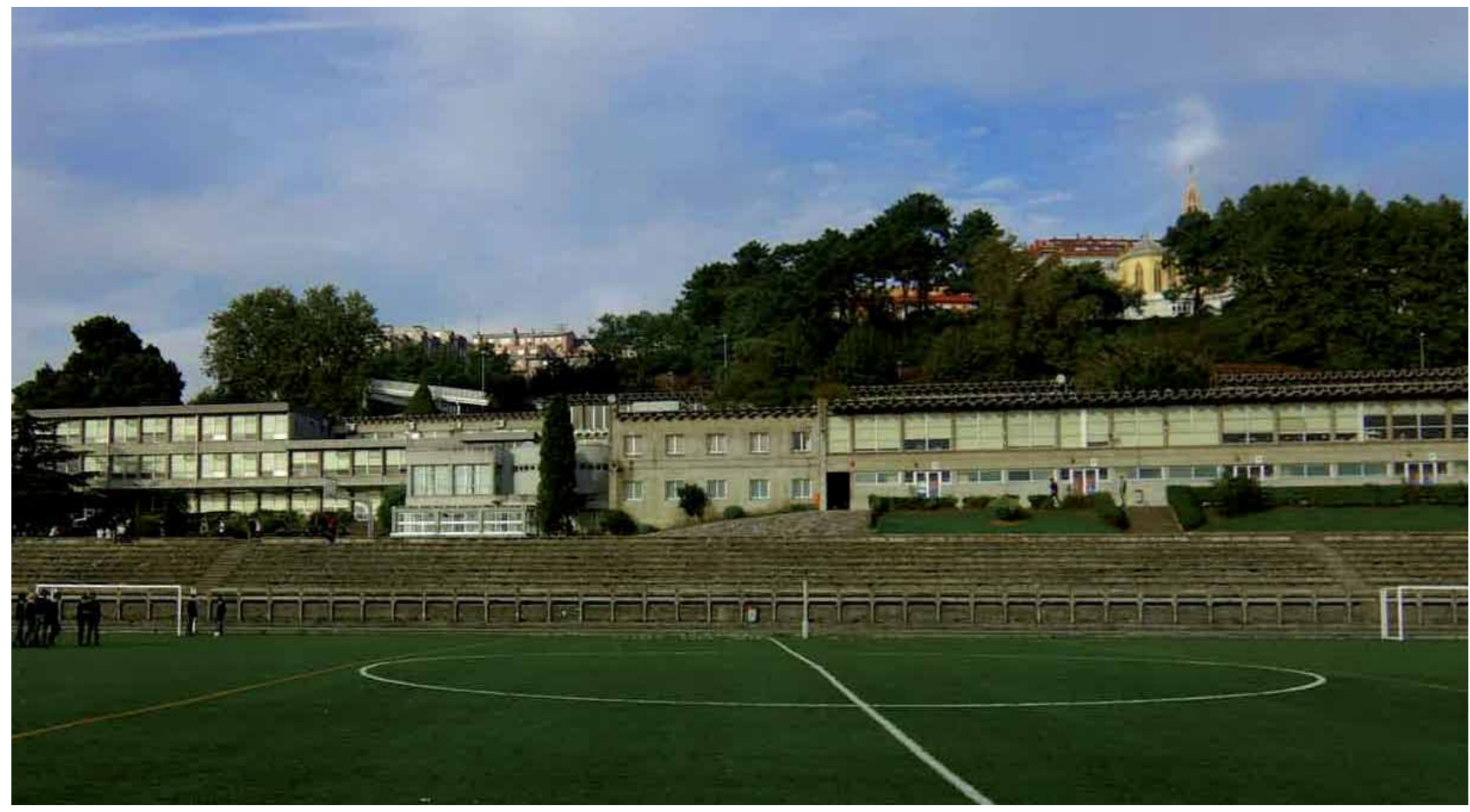

\section{Editoriales e intercambios}

Aguilar, Ceac, E. Palabra, Editorial San Pio X, Eunsa, Herder, Marsiega, Mensajero, Morata, Narcea, Paidós, SM, Unav, comenzaron a editar colecciones con libros puntuales sobre padres y educación de los hijos.

Surgió entonces la necesidad de intercambio entre la dirección de la Revista Padres y Maestros y otras revistas próximas a su temática. Y se creó la Biblioteca.

Más tarde el intercambio se amplió a temas educativos y de especialidad didáctica sobre diversas asignaturas.

Finalmente, la Biblioteca PyM se amplió considerablemente con la recepción de libros y otras publicaciones, documentos, medios audiovisuales sobre escuelas de padres, educación familiar, pedagogía y didáctica general y específica de asignaturas.

\section{Nuevos horizontes}

1996-2010. Nueva dirección de la revista en el colegio Santa María del Mar, dirección de Antonio Allende, Sergio Gómez Parra y de Ismael García Núñez.

La revista se hizo más abierta y estableció una nueva estructura estudiando temas importantes en la educación y pedagogía, dejando la subdivisión en secciones de temas evolutivos, personales, pedagógicos, didácticos, etc., que tenían como fin el desarrollo concreto de temáticas para su estudio en las reuniones de padres y maestros en el colegio.

En septiembre de 2010 la gestión de la revista Padres y Maestros y de la Biblioteca PyM se traslada a la Universidad Pontificia Comillas en Madrid y se hace cargo su actual director el profesor Vicente Hernández.

En este curso 2015-2016 celebramos con alegría su 50 aniversario con el deseo después del largo recorrido realizado durante todos estos años de que continúe con fidelidad creativa cumpliendo su misión fundacional.

Gracias a todos los que con su entrega desinteresada han hecho y siguen haciendo posible este proyecto editorial que constituye un importante legado de la historia de la educación en nuestro país •

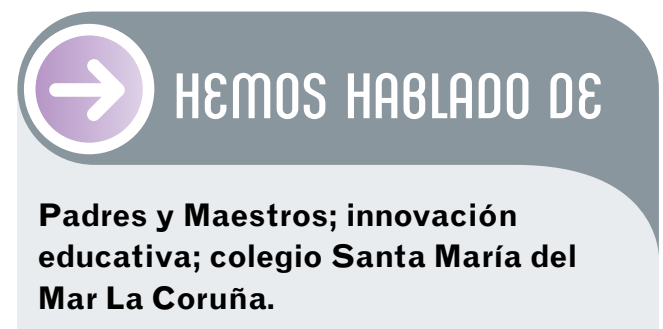

Este artículo fue solicitado por PADRES y MAESTROS en septiembre de 2015, revisado y aceptado en enero de 2016.
Colegio Santa María del Mar 